\title{
EFFECT OF LEUCINE-RICH WHEY PROTEIN AS COMPARED TO SOY PROTEIN ON MUSCLE FUNCTION IN ELDERLY INDIVIDUALS WITH OSTEOPENIA. A FOUR MONTH RANDOMIZED STUDY
}

\author{
J.L. Mehlsen, S.B. Pedersen, K.I. Nørgaard, B.L. Langdahl, N. Møller, B. Richelsen
}

\begin{abstract}
Objective: This investigation was conducted to determine whether dietary supplementation with a specific leucine-rich whey protein compound improves physical function and muscle strength in osteopenic elderly people compared to soy protein and placebo. Design, participants and setting: The study was a 16-week randomized single blinded placebo controlled intervention, including 47 women and 10 men from 60-85 years of age with osteopenia (T-score < -1.0 by dual energy X-ray absorptiometry scan). The subjects were assigned to three groups in 2:2:1 relations, daily receiving 1$)$ whey (45.8 g protein including $6.14 \mathrm{~g}$ leucine $(n=24)), 2)$ soy $(45.9 \mathrm{~g}$ protein with $3.1 \mathrm{~g}$ leucine $(\mathrm{n}=23))$, and 3$)$ isocaloric placebo with maltodextrin ( $\mathrm{n}=10)$. A home based resistance training protocol ( $3 \times 45 \mathrm{~min} /$ week) was followed by all groups concurrently. The primary focus of the study was on the differences between the two protein groups. Measurements: Physical function was determined by six-minute walk (6MW) and four-meter gait speed (4MGS) tests as primary endpoints, and strength (maximum voluntary contraction) by hand grip, leg extension and -flexion as secondary endpoints. Results: 6MW increased significantly in the whey group compared to the soy group $(4 \%$ as compared to $1 \%$ increment, $\mathrm{P}<0.05)$ but no changes were found in $4 \mathrm{MGS}$. There were no differences between any groups in other variables such as in the strength and balance tests. However, p-urate was significantly lower after whey protein as compared to soy $(\mathrm{P}<0.01)$. Conclusions: Four months of leucine-rich whey protein supplementation and concurrent resistance training significantly increased the six-minute walk test in elderly individuals as compared to soy protein. However, whether this minor increment in the walk test is of clinical importance is unknown. There was no effect on the four-meter gait speed or any other secondary muscle function-related endpoints.
\end{abstract}

Key words: Whey protein, soy protein, resistance training, physical function, elderly.

Abbreviations: DXA: dual energy x-ray absorptiometry; HOMA: homeostatic model assessment; MPS: muscle protein synthesis; MPT: muscle protein turnover; mTor: mechanistic target of rapamycin; LM: lean mass; FM: fat mass; RT: resistance training; 6MW: six-minute walk; ALAT: alanine amino transferase; 4MGS: four-meter gait speed; BMI: body mass index; MVC: maximum voluntary contraction; VO2 max: maximal oxygen uptake; IGF-1: insulin growth factor 1; NSB: normal standing balance; STB: semi tandem balance; TB: tandem balance; RPE: rated perceived exertion.

\section{Introduction}

Maintaining physical independence, high function and health is crucial for the elderly population and these factors are dependent on both muscle mass and muscle function. With prolonged muscle disuse due to e.g. disease or surgery, a significant loss of muscle mass and strength may occur and consequently follow the patient

Department of Endocrinology and Internal Medicine MEA, Tage-Hansens Gade 2 and Nørrebrogade, Aarhus University Hospital, 8000 Aarhus C, and Department of Clinical Medicine, Aarhus University, Denmark

Corresponding Author: Jesper L Mehlsen, Department of Endocrinology and Internal Medicine MEA, Tage-Hansens Gade 2 and Nørrebrogade, Aarhus University Hospital, 8000 Aarhus C, and Department of Clinical Medicine, Aarhus University, Denmark, jlme@clin.au.dk throughout persisted lifetime(1). In order to prevent agerelated loss of muscle mass and muscle function, often referred to as sarcopenia (2), both dietary approaches and physical activity may be beneficial (3).

The current recommended daily allowance (RDA) of protein intake is $0.8 \mathrm{~g} / \mathrm{kg}$ in elderly people and this amount has in recent years been discussed intensely (4). Recent data support an increase in protein intake to at least 1-1.2 (5) or 1.5 (6) $\mathrm{g} / \mathrm{kg} /$ day for healthy elderly people past 65 years of age, and to more than $1.2 \mathrm{~g} / \mathrm{kg} /$ day for elderly patients with acute or chronic diseases in order to prevent age-related diseases. The ketogenic amino acid leucine most abundant in whey protein is known to stimulate muscle protein synthesis (MPS) in humans possibly via interacting with the mTor pathway 
(7). Exercise in combination with nutrients may have an additional positive effect on muscle mass and muscle function, among other pathways also through activation of the mTor pathway in the muscle $(8,9)$. As regards MPS, it has been shown that elderly individuals per meal have a rather high anabolic threshold for dietary protein/amino acid, corresponding to $25-30 \mathrm{~g}$ protein per meal containing 2.5-2.8 g leucine (6) as compared to younger subjects where the MPS seems to be stimulated to its maximum with as little as $1.7 \mathrm{~g}$ leucine in $20-40 \mathrm{~g}$ high quality protein and the amount of leucine seems to be the important factor (10). Cuthbertson et al. have demonstrated an age related reduced activity in the mTor pathway, which may be of importance for the muscle wasting in the elderly, since they found decreased phosphorylation of downstream sites in the mTor pathway in elderly compared to younger men (11).

While the more acute effect of dietary protein in stimulating MPS is well described (6-11), the long term effects on targets such as muscle mass and physical function are more uncertain (12-14).

A newly published study from Bauer et al. found an increase in appendicular muscle mass and improved "chair stand test" after 13 weeks of treatment with daily supplements of $40 \mathrm{~g}$ whey protein including $6 \mathrm{~g}$ leucine compared to placebo in 302 men and women with sarcopenia (15). In line with this finding, Dillon et al. found a $3.9 \%$ increase in lean mass (LM) in 14 elderly women after intake of $15 \mathrm{~g}$ essential amino acids (EAA) with $2.78 \mathrm{~g}$ leucine versus placebo over 3 month (16), whereas, Verhoeven et al. found no effect on LM of 7.5 $\mathrm{g}$ leucine daily versus placebo in 30 elderly men after 3 month (17).

Thus, it is still unclear whether one protein source (e.g. whey versus vegetable) is better than another and, moreover, whether the level of particularly leucine has specific effects on muscle function/strength in elderly individuals. We, therefore, hypothesized that a supplement of leucine-rich whey protein together with resistance training (RT) would result in improvement of physical function and muscle strength among elderly individuals. We examined the viability of this intervention by comparing the whey protein with high leucine to a commercially available high quality vegetable soy protein with the same amount of total protein but with half the amount of leucine, for improving habitual everyday life activities as determined by a six-minute walk test (6MW) and a four-meter gait speed test (4MGS)

\section{Materials and Methods}

The study was a four month randomized controlled single blinded parallel intervention where the effects of two protein supplements (leucine-rich whey and soy protein), and a placebo supplement (maltodextrin) were studied in elderly men and women. The study was conducted at the Department of Endocrinology and Internal Medicine, Aarhus University Hospital. Participants were living independently and were recreationally active but not athletically active. The study protocols and procedures were conducted according to the Helsinki declarations and were approved by the ethics committee of the Central Region of Denmark. All participants signed a written informed consent. The study was registered by the number NCT01900548 at ClinicalTrials.gov.

\section{Subjects}

The participants were recruited between January 2014 and September 2015 from the Department of Endocrinology and Internal Medicine and the Department of Geriatric, Aarhus University Hospital, Denmark. The inclusion criteria were age between 60-85 years and osteopenia. Osteopenia was determined by a T-score <-1 (DXA scan) in the lumbar spine or in the hip as a part of an osteoporosis screening procedure at the hospital. Exclusion criteria were severe heart disease (NYHA class $>2$ ), $3 \times$ upper level of normal alanine aminotransferase (ALAT) (for women $>135 \mathrm{U} / \mathrm{L}$ and for men $>210 \mathrm{U} / \mathrm{L}$ ), s-creatinine $>130 \mu \mathrm{mol} / \mathrm{L}$, diabetes $(\mathrm{HbA} 1 \mathrm{c} \geq 6.5 \%(\geq 48 \mathrm{mmol} / \mathrm{mol}))$, current corticosteroid treatment or treatment within the last 3 months, previous hip or vertebral fracture, any specific anti-osteoporotic treatment and $25-\mathrm{OH}$ vitamin-D $<30 \mathrm{nmol} / 1$.

\section{Study design}

The subjects were randomized into one of the three following groups: 1) Whey group (leucine-rich), 2) soy group, and 3) placebo which was isocaloric with the two protein groups (Table 1). All participants in the three groups received two tablets of UniKalk forte (Orkla, Ishøj, Denmark) containing a total of $38 \mu \mathrm{g}$ vitamin D3 and 800 $\mathrm{mg}$ calcium daily during the intervention.

99 individuals requested and received detailed oral information about the study, and 86 subjects were found eligible. In the following screening procedure, three individuals were excluded in accordance to the exclusion criteria, and five subjects refused further participation. Thus, 78 subjects were included in the intervention study (fig. 1). The randomization process was as follows: With a block randomized procedure subjects were randomized in blocks of five in 2:2:1 relations between the whey group, the soy group, and the placebo group. Since all groups received RT (see below) - the placebo group - was included to determine the possible protein-independent effect of the physical training. During the intervention we used a dropout replacement procedure to ensure that the relationship between the groups was maintained despite different dropout rates in the three groups - as described elsewhere (18). The soy protein group was most frequently affected by dropout replacement as 15 subjects withdrew early due to the following: nausea 
and bad taste $(\mathrm{n}=7)$, physical complications $(\mathrm{n}=3)$, illness $(n=3)$, personal reasons $(n=1)$, and one was excluded due to $\mathrm{HbA} 1 \mathrm{c} \geq 6.5 \%$. In the whey group four subjects withdrew early due to physical complications $(n=3)$ and illness $(\mathrm{n}=1)$. In the placebo group two subjects withdrew early due to illness and a skin rash. Therefore, 28, 38 and 12 subjects were randomized to the whey, the soy and the placebo groups, respectively. During the intervention there was a total dropout of 21 subjects. Finally, we ended up with a total of 24,23 and 10 subjects who completed in the whey group, the soy group, and the placebo group, respectively (fig. 1)

Table 1

Nutritional composition of the intervention supplements

\begin{tabular}{lccc}
\hline & $\begin{array}{c}\text { Whey protein } \\
\text { supplement }\end{array}$ & $\begin{array}{c}\text { Soy protein } \\
\text { supplement }\end{array}$ & $\begin{array}{c}\text { Placebo } \\
\text { (maltodextrin) } \\
\text { supplement }\end{array}$ \\
\hline Protein, g & 45.8 & 45.9 & 0 \\
Leucine, \% of protein & 13.4 & 6.74 & 0 \\
Isoleucine, \% of protein & 6.1 & 4.04 & 0 \\
Lysine, \% of protein & 11.11 & 5.24 & 0 \\
Arginine, \% of protein & 2.74 & 6.39 & 0 \\
Asparagine, \% of protein & 12.64 & 9.79 & 0 \\
Glutamic acid, \% of protein & 18.25 & 16.1 & 0.2 \\
Fat, g & 0.4 & 2.7 & 66.6 \\
Carbohydrate, g & 19 & 20 & 265.1 \\
Energy content, kcal/day & 260.6 & 285.9 & 0 \\
\hline
\end{tabular}

The supplemental nutrients and energy taken per day in the three groups during the intervention. Extra leucine was added to the whey protein supplement.

\section{Figure 1}

Flow chart of the protein supplementation intervention. Three of the completed subjects were excluded from the analysis due to low compliance or illness (two from the whey group, one from the soy group). A dropout replacement procedure was used to ensure equal group sizes when exposed for high withdrawal

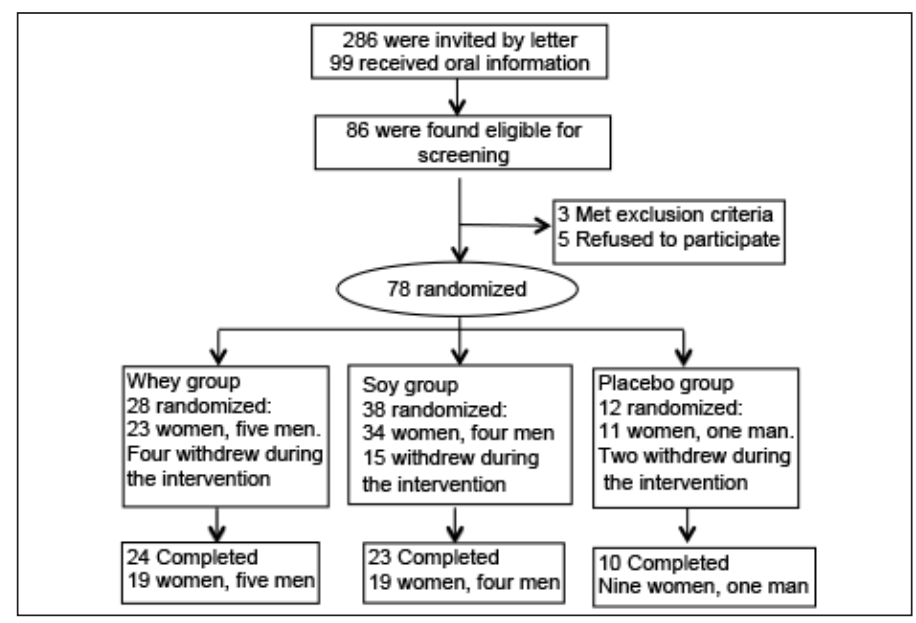

\section{The Supplemetation}

Total supplemented protein and leucine per day were in the whey group $45.8 \mathrm{~g}$ and $6.14 \mathrm{~g}$, respectively, and in the soy group $45.9 \mathrm{~g}$ and $3.1 \mathrm{~g}$, respectively. No protein or leucine was included in the placebo group supplementation (Table 1). The whey protein and the placebo product were produced and delivered by Arla Foods Ingredients Group P/S (Denmark). The soy protein was commercially available from Soya International (Hale, UK).

The supplements were delivered in foil packs in 35.3 g powder to be constituted with approximately 150 $\mathrm{ml}$ of water. The subjects were instructed to consume the supplement twice daily as a part of the breakfast and lunch (15). Due to the exercise induced metabolic window theory, the subjects were instructed to ingest one supplement just after exercise on training days (19). The supplements were flavored neutrally or with chocolate. After 16 weeks we collected unused full foil packs to calculate compliance according to the protocol (fig.1).

Table 2

Baseline clinical characteristics of the participants (completers)

\begin{tabular}{lccc}
\hline & $\begin{array}{c}\text { Whey group } \\
\mathbf{n = 2 4} \mathbf{( 5 )}\end{array}$ & $\begin{array}{c}\text { Soy group } \\
\mathbf{n = 2 3}(\mathbf{4})\end{array}$ & $\begin{array}{c}\text { Placebo group } \\
\mathbf{n = 1 0}(\mathbf{1})\end{array}$ \\
\hline Age (years) & $68.6 \pm 5$ & $69 \pm 4.3$ & $67.6 \pm 3.6$ \\
Weight (kg) & $67.3 \pm 10.9$ & $65.8 \pm 13$ & $69.7 \pm 9.1$ \\
BMI (kg/m2) & $25 \pm 3.4$ & $24.5 \pm 4$ & $26.8 \pm 4$ \\
LM (kg) & $39.8 \pm 8.7$ & $38.6 \pm 9.1$ & $38.1 \pm 4.9$ \\
FM (kg) & $22.9 \pm 5.8$ & $22.4 \pm 6.3$ & $27.4 \pm 6.4$ \\
FM (\%) & $35.7 \pm 7.2$ & $35.6 \pm 6.9$ & $40.6 \pm 5.5$ \\
6MW (m) & $575.1 \pm 61.2$ & $591.7 \pm 62.5$ & $593.1 \pm 78.3$ \\
Vo2max (ml/ kg/min) & $27.2 \pm 9.4$ & $29.6 \pm 10.3$ & $25.2 \pm 8.7$ \\
BMD Total (g/cm2) & $0.969 \pm .07$ & $0.945 \pm .05$ & $0.980 \pm .06$ \\
BMD Lumbar spine $(\mathrm{g} / \mathrm{cm} 2)$ & $0.857 \pm .09$ & $0.845 \pm .06$ & $0.883 \pm .08$ \\
\hline
\end{tabular}

All values are mean \pm SDs. 57 participants with osteopenia and age between $60-85$ years was included in this 16 -week intervention. The number of participants in the three groups is given together with the number of men in parenthesis. There were no statistical differences at baseline between the three groups; (ANOVA). Fat mass (FM), Lean mass (LM), Six-minute walk (6MW), Energy percentage (E\%).

\section{Dietary assessment}

Three day weighed food records were conducted by a trained dietician at baseline and in the end of the study (week 16). The 47 subjects who completed the food records had all received guidance in how to register their foods and drinks without including the protein or placebo supplements. In the week 16 assessment of dietary intake we included compliance data to approximate per meal intakes. Food records were analyzed by the Dankost pro program version 1.5.49.21 (Dankost, Copenhagen, DK). The total energy intake was expressed in kilo joule 
per day $(\mathrm{KJ} / \mathrm{d})$ (Table 3$)$. The total protein intake was expressed as percentage of total energy intake $(\mathrm{E} \%)$, and as g per $\mathrm{kg}$ body weight per day (g/ kg/day). Additionally leucine was expressed in g per day.

Table 3

The diet during the study - baseline values and changes

\begin{tabular}{lccc}
\hline & Whey & Soy & Placebo \\
\hline Total energy intake: & & & \\
Baseline (Kj/d) & $7307 \pm 2357$ & $6691 \pm 1617$ & $7021 \pm 1662$ \\
Post (Kj/d) & $7099 \pm 2227$ & $6434 \pm 1931$ & $6068 \pm 1775$ \\
Post + sup. (Kj/d) & $8068 \pm 2244$ & $7513 \pm 1943^{* *}$ & $7074 \pm 1770$ \\
Protein energy intake: & & & \\
Baseline (E\%) & $17 \pm 4.1$ & $18.2 \pm 3.4$ & $17.4 \pm 2.8$ \\
Post (E\%) & $16.5 \pm 3.9$ & $18.41 \pm 4.15$ & $17.1 \pm 3.68$ \\
Post + supp. (E\%) & $23.4 \pm 4.0 \mathrm{p}^{* * *}$ & $25.4 \pm 5.0 \mathrm{p}^{* * *}$ & $14.5 \pm 3.1^{*}$ \\
Protein intake: & & & \\
Baseline (g/kg) & $1.08 \pm 0.3$ & $1.09 \pm 0.2$ & $1.03 \pm 0.3$ \\
Post (g/kg) & $1.02 \pm 0.3$ & $1.05 \pm 0.3$ & $0.87 \pm 0.3$ \\
Post + supp. (g/kg) & $1.64 \pm 0.4 \mathrm{p}^{* * *}$ & $1.71 \pm 0.4 \mathrm{p}^{* * *}$ & $0.87 \pm 0.3^{*}$ \\
Leucine intake: & & & \\
Baseline (g/day) & $3.98 \pm 1.40$ & $4.04 \pm 1.10$ & $3.94 \pm 0.62$ \\
Post (g/day) & $4.01 \pm 1.49$ & $3.75 \pm 1.67$ & $3.71 \pm 1.09$ \\
Post + sup. (g/day) & $9.44 \pm 1.51 \mathrm{c}, \mathrm{pp} \mathrm{p}^{* * *}$ & $6.75 \pm 1.47 \mathrm{p}^{* *}$ & $3.71 \pm 1.09$ \\
\hline All & & & \\
\hline
\end{tabular}

All values are mean $\pm \mathrm{SD}$, The dietary data after the intervention ("post") are given both without and with the supplementation. The data in relation to baseline and after the intervention values are obtained from the food records. ${ }^{*} ;{ }^{* *}$ and ${ }^{* * *}$ denotes significantly different from baseline at level $\mathrm{p}<0.05 ; \mathrm{p}<0.01$ and $p<0.001$ respectively. $p$ and $p p$ denotes different from placebo group at level $p<0.001$ and $p<0.0001$ respectively. $C$ denotes significant different between the protein groups $\mathrm{p}<0.001$.

\section{Resistance training}

All participants in the three groups underwent a RT program for 45 minutes three times a week during the whole intervention. The RT protocol has been developed and recommended by others $(20,21)$. The training program was homebased training with supervision every second week. The training was conducted with TheraBand elastic bands (PROcare, Roskilde, Denmark) which has been used and validated in an elderly population $(22,23)$. Exercise progression and adherence to the training program was quantified by training records reporting rated perceived exertion (RPE) and level of resistance (22). The training intensity was increased during the intervention in level of RPE and number of repetitions. From week 0-4 the exercise were conducted as sets of $3 \times 15$ at level $\mathrm{RPE}=5$ increasing intensity in week 5-7 to $3 \times 15$ at level $\mathrm{RPE}=7$ and further in week 8-16 to $3 \times 10$ at level $\mathrm{RPE}=7$. Every second week the exercise was conducted at the University Hospital with professional supervision. At these sessions the exercise was conducted as a circuit training regimen for potentially greater achievements as suggested elsewhere (20).

\section{Determination of physical function, body composition, strength and balance}

The primary endpoints in this study were testing of physical function by the $6 \mathrm{MW}$ and the 4MGS tests. The 6MW test is easy to administer, more reflective of activities of daily living and better tolerated than other walk tests (24). The subjects were instructed to walk as fast as possible, without further encouragement (24). The test was performed in a 30 meter corridor twice at baseline for familiarization (the better of the two was used) and once at the end of the intervention (24). Moreover, a consensus panel that considered reliability of the 6MW and the 4MGS test had recommended these tests as performance measures in older adults (25).

At baseline the 4MGS test was performed twice on two separate days for familiarization. The better of the two tests on the second test day was used as the baseline outcome. Post intervention the test was conducted twice and the better test was used as the 16 week outcome. 4MGS is a commonly used test in elderly, it predicts better survival (26), and there is a nonlinear relationship between 4MGS and leg strength (27).The non-linear relationship represents a mechanism by which small increments in leg strength in frail elderly may produce large improvements in gait speed, while large changes in leg strength in healthy people have no effect on gait speed.

\section{Body composition and weight}

The whole body composition was estimated using DXA scan (Hologic Discovery, Waltham, USA). All DXA assessments (pre and post intervention) were conducted at the same time point in the afternoon on the same scanner. The present study focuses on total lean mass (LM) in $\mathrm{kg}$ excluding bones and on fat mass (FM). Body weight was determined by weighing the subjects wearing easy clothing by electric scales Tanita WB-110 P MA, and height was determined by a stadiometer SECA model 220. BMI was calculated as weight $/$ heigth ${ }^{2}\left(\mathrm{~kg} / \mathrm{m}^{2}\right)$.

\section{Strength tests}

Strength tests of hand grip, leg flexion and leg extension were measured in an adjustable dynamometer chair (Good Strength, Metitur Ltd, Finland). Subjects were encouraged to perform maximum voluntary contraction (MVC) in three $x$ five seconds with 30 seconds rest between each attempt. All tests were performed in a neutral sitting upright position; hand grip test with a $90^{\circ}$ angled and supported elbow joint, and leg extension and flexion tests with the knee joint fixed in a $90^{\circ}$ angle and the ankle and thigh fastened by a belt. The leg extension and flexion isometric MVC was measured in the fixed position moving the leg towards an extended 
EFFECT OF LEUCINE-RICH WHEY PROTEIN AS COMPARED TO SOY PROTEIN ON MUSCLE FUNCTION IN ELDERLY INDIVIDUALS WITH OSTEOPENIA

and flexed position, respectively. For all strength tests, the mean of the three attempts was used in the statistical analysis. Because of method limitation (temporary error in the dynamometer), the reduced number of subjects completing the three strength tests were $n=20, n=18$ and $\mathrm{n}=7$ in the whey, soy and placebo groups respectively.

\section{Balance tests}

Balance tests were performed on an equilateral triangular force platform connected to a computer-based system (Good BalanceTM, Metitur Ltd, Finland). Balance was tested with increasing difficulty in the following three tests: Normal standing balance (NSB), semi tandem balance (STB), and tandem balance (TB). The balance was measured as a velocity in sway, and the tests are described in details elsewhere (28). An improvement in balance is here expressed as a relative reduction in \% compared to baseline.

\section{Estimated maximal oxygen uptake (VO2 max)}

Functional capacity was determined by the Aastrand ergometer test for estimating VO2 max. The workload was determined in steady state after six minutes of submaximal work and a heart rate just above 110 beats per minute (bpm). The Aastrand test is a gentle submaximal test and it has been validated as a reliable estimate of $\mathrm{VO} 2 \max (29)$.

\section{Blood sampling and analysis}

After an overnight fast (at baseline and postintervention) blood samples were collected in tubes containing EDTA and immediately centrifuged at $4^{\circ} \mathrm{C}$ over 10 minutes at $1500 \mathrm{x}$ g. Tubes with plasma were stored at $-80^{\circ} \mathrm{C}$ for further analysis. Glucose and insulin were analyzed in-house with the Glucose GOD-PAP method (Roche Dianostics, Hvidovre, Denmark) for glucose analysis and an enzyme-linked immunoassay (DAKO, Glostrup, Denmark) for insulin analysis. IGF-1 was analyzed by IDS-iSYS IGF-1 assay (immunodiagnostic systems Ltd, Boldon, England).

Urate was determined by an enzymatic colorimetric method (Roche/Hitachi cobas c 501, Roche Diagnostics $\mathrm{GmbH}$ ). Urea concentration was quantified by kinetic test with urease and glutamate dehydrogenase (Roche/ Hitachi cobas c 501, Roche Diagnostics GmbH). All samples were analyzed on EDTA-plasma. All measures for each patient were assessed on the same batch except from urea. The analytical coefficients of variance were for insulin $<10 \%$, glucose $<3 \%$, IGF- $1<8 \%$, Urate $<13 \%$ and for urea $<2 \%$.

\section{Statistics}

The expected change between the two protein groups in $6 \mathrm{MW}$ and $4 \mathrm{MGS}$ was $50 \mathrm{~m}$ and $0.1 \mathrm{~m} / \mathrm{s}$, respectively as recommended by others (30). With 23 subjects in each group, our requirements of a significant level at $\mathrm{P}<0.05$ with a power of $80 \%$ were contented (30).

Our aim was having 28 subjects in each protein group and 14 in the placebo group. It was decided to recruit a total of $80-85$ subjects, as a $10-15 \%$ early withdrawal range was expected from our previous experiences.

The main comparison of interest in this study was between the two protein supplementation groups, whey $n=24$ and soy $n=23$. All data were from independent observations, and normal distribution in the three groups was tested by QQ plots, and difference in variance was tested by the Bartletts test for equal variances. At baseline data that were not normally distributed were log transformed before further statistical analysis and presented as medians with 95\%-CI. For all normal distributed data, values are presented as means \pm SDs. Differences in outcome means between the whey, soy and placebo groups were analyzed by the ANCOVA model. The dependent variables were adjusted for the covariates BMI, age, sex and baseline levels when assumption of a significant linear association between the dependent variable and the covariate was contented. These specific covariates were chosen because of their shown impact on the outcome measures. One-way analysis of variance (ANOVA) tested for differences between groups at baseline, and paired t-tests were used for calculating within-group differences from baseline to post intervention. The statistical analyses were performed as a per protocol analysis.

The statistical analyses were performed by Stata version 13 and the graph by Graphpad Prism 5.

\section{Results}

\section{Subjects characteristics}

The baseline characteristics of the 57 individuals ( 47 women and 10 men) who completed the intervention (fig. 1) are shown in Table 2. At baseline the three groups were comparable according to age, BMI, weight, LM, FM, VO2 max and 6MW. The mean age of the subjects was 68.6 years and the mean BMI was $25.1 \mathrm{~kg} / \mathrm{m}^{2} \pm 3.8$. The activity level was similar in the three groups and all participants were living independently. Moreover, the $6 \mathrm{MW}$ test was similar between the three groups. As shown in Table 3 there were no differences between any groups in total energy intake, protein or leucine intake at baseline. Only one of the participants smoked.

The compliance to the supplements was $89 \% \pm 7.9$ without differences between the groups (whey $87.8 \% \pm$ 9.4, soy $89.6 \% \pm 7.7$, placebo $90.1 \% \pm 4.3$ ). Two subjects were excluded from the analysis due to not following 
the protocol (one subject had cognitive limitations that affected managing the RT, furthermore the subject only ingested $57 \%$ of the supplements and another had stopped taken the supplements 3 weeks before the end of the study), and one subject was excluded due to illness. $72 \%$ of the subjects completed the training log and, 16 subjects $(28 \%)$ failed to complete their training log. Compliance to the RT protocol was in the log book found to be $87.9 \% \pm 15.9$ without differences between the groups (whey $86.8 \% \pm 15.8$, soy $89.8 \pm 17.8$, placebo $86.4 \pm 15$ ).

\section{Changes in physical function during the intervention}

The 6MW test increased in both protein groups but more in the whey group (by $22.8 \mathrm{~m} \pm 26.7$ corresponding to a $4.0 \%$ increment) as compared to the soy group (5.8 $\mathrm{m} \pm 18.1$ corresponding to a $1.0 \%$ increment) and this difference between the two groups was significant $(\mathrm{P}<0.05$ fig. 2$)$. Moreover, in the placebo group 6MW was increased by $14.1 \mathrm{~m} \pm 16.2(2.4 \%)$ which was not significantly different from the two protein groups. Compared to baseline levels 6MW increased significantly in the whey and placebo groups $(\mathrm{P}<0.001$ and $\mathrm{P}<0.05$, respectively) but not in the soy group (NS).

Concerning the 4MGS test there were no differences neither between the two protein groups nor within any of the three groups in relation to baseline levels. Moreover, VO2 max was unaffected in the three groups (Table 4).

Concerning the strength tests (handgrip, leg flexion and -extension), there were no differences between the two protein groups (Table 4). The handgrip strength increased, however, in all three groups compared to baseline but only significantly in the soy group, by $34.7 \mathrm{~N}$, (11.6\%, $\mathrm{P}<0.05$, Table 4)

Leg extension strength also increased in all three groups with significant increases within both the whey group by $24.7 \mathrm{~N} \pm 43(8 \%, \mathrm{P}<0.05)$ and the soy group by $43.1 \mathrm{~N} \pm 40.1(17.1 \%, \mathrm{P}<0.001)$, and a trend towards an increase within the placebo group by $42.8 \mathrm{~N} \pm 54.3$ (15.9\%, $\mathrm{P}=0.08$ ) which may suggest an effect of the exercise intervention on MVC in leg extension in all the groups.

MVC in leg flexion increased by $16.8 \mathrm{~N} \pm 33.6(\mathrm{P}<0.05)$ and $22.0 \mathrm{~N} \pm 20.8(\mathrm{P}<0.001)$ in the whey and soy protein groups respectively, and when calculated together as one protein group there was a tendency towards a protein effect on MVC in leg flexion $(\mathrm{P}=0.16)$ compared to placebo.

There were no changes between any of the groups in any of the balance tests (Table 4). Balance performance was generally improved as sway velocity was relatively reduced compared to baseline (2-29\%), though only significantly in NSB in the whey group by $20 \%$ with $95 \%$-CI $(-35 ;-3)$, and in the placebo group by $29 \%$ with $95 \%$-CI $(-46 ;-5)$ (Table 4). There was also a trend towards improvement in TB in whey $(\mathrm{P}=0.056)$ and soy $(\mathrm{P}=0.067)$ as well as in STB in soy $(\mathrm{P}=0.17)$ and the placebo group $(\mathrm{P}=0.16)$.

\section{Changes in body weight and body composition}

There were no differences in body weight between the groups (Table 4). As compared to baseline body weight increased in all three groups - in the whey group by $0.43 \mathrm{~kg} \pm 1.1$ (NS) and in the soy group by $0.26 \mathrm{~kg} \pm 1.3$ (NS), and significantly in the placebo group by $1.03 \mathrm{~kg}$ $\pm 1.4(\mathrm{P}<0.05)$ (Table 4).

\section{Table 4}

Changes in physical function and body composition during the intervention

\begin{tabular}{lccc}
\hline & $\begin{array}{c}\text { Whey }(\mathbf{n}=22) \\
\text { change }\end{array}$ & $\begin{array}{c}\text { Soy }(\mathbf{n}=22) \\
\text { change }\end{array}$ & $\begin{array}{c}\text { Placebo (n=10) } \\
\text { change }\end{array}$ \\
\hline Physical function & & & \\
6MW (m) & $22.8 \pm 26.7^{\text {C *** }}$ & $5.8 \pm 18.1$ & $14.1 \pm 16.2^{*}$ \\
4MGS (s) & $-0.1 \pm 0.33$ & $0.02 \pm 0.21$ & $0.04 \pm 0.32$ \\
Vo2max (mlo2/kg/min) & $0.28 \pm 4.35$ & $0.74 \pm 5.1$ & $-0.3 \pm 3.1$ \\
Hand grip (N) & $9.9 \pm 37.8$ & $34.7 \pm 52.7^{*}$ & $19.6 \pm 50.2$ \\
Leg extension(N) & $24.7 \pm 43^{*}$ & $43.1 \pm 40.1^{* * *}$ & $42.8 \pm 54.3$ \\
Leg flexion (N) & $16.8 \pm 33.6^{*}$ & $22.0 \pm 20.8^{* * *}$ & $2.3 \pm 11.4$ \\
NSB (\%) & $-20(-35 ;-3)^{*}$ & $-8(-23 ; 11)$ & $-29(-46 ;-5)^{*}$ \\
STB (\%) & $-12(-30 ; 9)$ & $-14(-32 ; 7)$ & $-18(-39 ; 10)$ \\
TB (\%) & $-18(-33 ; 1)$ & $-18(33 ; 6)$ & $-2(-20 ; 19)$ \\
Body composition & & & \\
Weight (kg) & & $0.260 \pm 1.3$ & $1.03 \pm 1.4^{*}$ \\
LM (kg) & $0.432 \pm 1.1$ & $0.545 \pm 0.9^{* *}$ & $0.226 \pm 1.0$ \\
FM (kg) & $0.157 \pm 1.03$ & $-0.186 \pm 1.11$ & $0.404 \pm 0.93$ \\
\hline All values & $0.137 \pm 1.26$ & &
\end{tabular}

All values are means \pm SDs or medians with $(95 \%-\mathrm{CI}), \mathrm{C}$ denotes significantly different between the two protein groups $\mathrm{p}<0.05$, calculated by ANOVA. *; ** and ${ }^{* * *}$ denotes significantly different from baseline in each group at the level of $\mathrm{p}<0.05 ; \mathrm{p}<0.01$ and $\mathrm{p}<0.001$, respectively, calculated by paired t-tests. Fat mass (FM), Lean mass (LM), Six-minute walk (6MW), four meter gait speed (4MGS), Newton (N), Normal standing balance (NSB), Semi tandem balance (STB), Tandem balance (TB).

There were no differences in LM or FM between any of the groups (Table 4). As compared to baseline levels, there was only a significant increment in LM in the soy group $(\mathrm{P}<0.01$, Table 4$)$. When the two protein groups were combined there was a tendency towards increased FM in the placebo group as compared to the protein groups ( $\mathrm{P}=0.06$ Table 4$)$.

\section{Changes in blood values during the intervention}

As shown in Table 5, there were no differences in changes in insulin, glucose, and HOMA index between any of the groups. As compared to baseline levels there was a significant increase within the whey group in insulin $(\mathrm{P}<0.05)$, glucose $(\mathrm{P}<0.05)$ and HOMA index $(P<0.05)$ but not in the other groups.

As compared to baseline IGF-1 increased in both protein groups - by $10.2 \mathrm{ng} / \mathrm{ml} \pm 15.3(9 \%, \mathrm{P}<0.01)$ within the whey group, and by $7.4 \mathrm{ng} / \mathrm{ml} \pm 11(7 \%, \mathrm{P}<0.01)$ within the soy group with no changes in the placebo 
group. There was a tendency towards an increase in IGF-1 concentration in the protein groups when combining the two protein groups as compared to the placebo group $(\mathrm{P}=0.065$, Table 5).

Table 5

Changes in blood values during the intervention

\begin{tabular}{lccc}
\hline & Whey $(\mathbf{n}=\mathbf{2 2})$ & Soy $(\mathbf{n}=\mathbf{2 2})$ & Placebo $(\mathbf{n}=\mathbf{1 0})$ \\
\hline 1Insulin $(\mathrm{pmol} / \mathrm{L})$ & $39.7 \pm 32$ & $37.1 \pm 30.2$ & $41.4 \pm 24.7$ \\
2Insulin $(\mathrm{pmol} / \mathrm{L})$ & $8.9 \pm 15.8^{*}$ & $5.6 \pm 22$ & $0.5 \pm 15.4$ \\
1Glucose $(\mathrm{mmol} / \mathrm{L})$ & $5.4 \pm 0.76$ & $5.9 \pm 0.7$ & $5.8 \pm 0.65$ \\
2Glucose $(\mathrm{mmol} / \mathrm{L})$ & $0.36 \pm 0.59^{*}$ & $-0.06 \pm 0.62$ & $-0.27 \pm 0.54$ \\
1HOMA-IR & $0.81 \pm 0.58$ & $0.8 \pm 0.54$ & $0.85 \pm 0.43$ \\
2HOMA-IR & $0.14 \pm 0.28^{*}$ & $0.08 \pm 0.4$ & $-0.04 \pm 0.3$ \\
1IGF-1 (ng/ml) & $119 \pm 29.4$ & $104.6 \pm 27.8$ & $111.8 \pm 18.3$ \\
2IGF-1 (ng/ml) & $10.2 \pm 15.3^{* *}$ & $7.4 \pm 11^{* *}$ & $0.1 \pm 19.3$ \\
1Urate (mmol/l) & $0.253 \pm 0.05$ & $0.281 \pm 0.06$ & $0.265 \pm 0.05$ \\
2Urate (mmol/l) & $-0.022 \pm 0.025^{\mathrm{c} * * *}$ & $-0.006 \pm 0.031$ & $-0.003 \pm 0.031$ \\
1Urea $(\mathrm{mmol} / \mathrm{l})$ & $5.68 \pm 1.02$ & $5.31 \pm 1.02$ & $5.82 \pm 0.89$ \\
2Urea $(\mathrm{mmol} / \mathrm{l})$ & $0.76 \pm 0.8 \mathrm{P}^{* * *}$ & $0.87 \pm 0.8 \mathrm{P}$ *** & $-0.29 \pm 0.6$ \\
\hline
\end{tabular}

All values are means \pm SDs, $C$ denotes significantly different between the two protein groups at level $\mathrm{p}<0.01$ calculated by ANOVA, $\mathrm{P}$ denotes significantly different from Placebo value $(\mathrm{p}<0.01)$ calculated by ANOVA. *; ** and *** denotes significantly different from baseline in each group at level $\mathrm{p}<0.05$; $p<0.01$ and $p<0.001$ respectively, calculated by paired t-tests. Insulin growth factor (IGF-1).1denotes baseline values, 2 denotes changes.

As expected the urea concentration increased significantly in both the whey protein group by 0.76 $\mathrm{mmol} / \mathrm{L} \pm 0.8(14.6 \%, \mathrm{P}<0.001)$ and in the soy protein group by $0.87 \mathrm{mmol} / \mathrm{L} \pm 0.8(17.6 \%, \mathrm{P}<0.001)$ compared to baseline with no changes between the two protein groups. Moreover, the increment in urea concentration in the protein groups was significantly different from the $4.8 \%$ decrease in the placebo group $(\mathrm{P}<0.001$, Table 5$)$.

The changes in urate were significantly different between the two protein groups $(\mathrm{P}<0.01$, Table 5) where urate decreased by $0.022 \mathrm{mmol} / 1 \pm 0.02(-7.5 \%)$ in the whey group compared with no changes in the soy group.

\section{Dietary changes during the study}

As expected there were no differences in total protein intake between the whey- and soy groups during the intervention $(1.64 \mathrm{~g} / \mathrm{kg} /$ day and $1.71 \mathrm{~g} / \mathrm{kg} /$ day, respectively) which was significantly different from the placebo group $(0.87 \mathrm{~g} / \mathrm{kg} /$ day $)(\mathrm{P}<0.001$, Table 3$)$. Moreover, also as expected the leucine content of the diet was significantly higher in the whey group $(9.44 \mathrm{~g} /$ day) as compared to the soy group (6.75 g/day) ( $\mathrm{P}<0.001$, Table 3$)$ and the placebo group (3.71 g/ day) $(\mathrm{P}<0.0001)$.

\section{Figure 2}

Effects of intake of whey protein and soy protein for 16 weeks on six-minute walk (6MW) distance. Mean changes of walk distance in meter + / - SEM. There was a significant difference between the whey and the soy group calculated by ANCOVA. Whey group $n=22$, soy $\mathrm{n}=22$, placebo $\mathrm{n}=10$

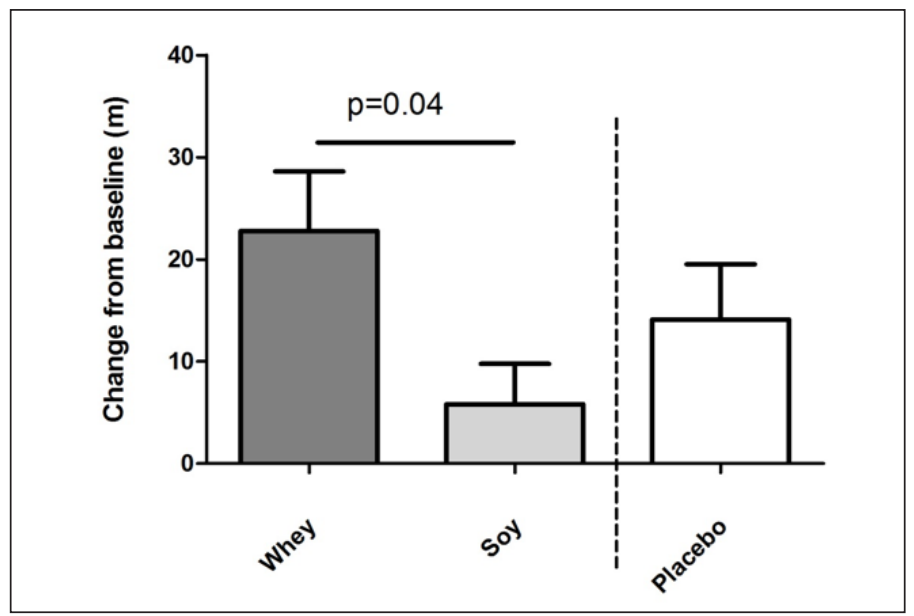

\section{Discussion}

In these elderly individuals with osteopenia, whey with leucine enrichment was found to significantly increase the $6 \mathrm{MW}$ test compared to soy protein supplementation, but no significant effects on 4MGS or any other physical performance or strength tests were seen between the two groups.

The clinical implication of the 3\% extra increment of $6 \mathrm{MW}$ in the whey group as compared to the soy group is difficult to evaluate but is rather small. It has been shown that a 50 meter change corresponding to an $8 \%$ increase could give a substantial clinical effect with group sizes like in our study (31).

Our finding that exercise and leucine rich whey protein increases physical function, although to a minor degree, determined by the $6 \mathrm{MW}$ test supports a recent investigation from Rondanelli et al., who reported that exercise and leucine supplementation increased physical function in hand grip strength by $20 \%$ compared to exercise and placebo (32). Furthermore, a recent pilot trial in elderly people reported a $5.8 \%$ and $8.8 \%$ increase in $6 \mathrm{MW}$ after EAA with $20 \%(\mathrm{n}=8)$ or $40 \%(\mathrm{n}=8)$ leucine, respectively, and only a $1.5 \%$ increase in the placebo group ( $n=9)(12)$. It is well known that essential amino acids and in particular leucine is associated with an increase in MPS in acute studies in humans $(33,34)$. It has been reported that the long term effect of an increase in MPS due to dietary protein might lead to increase in LM and physical function, also in elderly people (16). In our study we saw no increase in LM, however, it has been demonstrated by others that physical function can improve without an increase in muscle mass (35, 36). Moreover, numerous recent publications in elderly individuals have demonstrated effects of dietary protein 
and EAA supplementation on a variety of physical function outcomes as leg extension and endurance (13), chair rise (15) and balance and gait speed (35).

We did not find any differences in strength and balance tests between any of the groups. However, there was a clear trend towards improvement in strength and balance, with significantly increased performance compared to baseline in several parameters across all groups. This may indicate an effect of the RT in this study like in other studies (37-39), and in line with recent reports on the associations between strength and balance in elderly individuals $(40,41)$. There were no differences between the two protein groups concerning anthropometrics such as body weight, LM and FM, but, there was a non-significant tendency that body weight and FM increased in the placebo group. This may be due to the maltodextrin (polysaccharide - glucose) which was given to this group, and high intake of glucose may enhance the risk of positive energy balance (42).

There were no differences between the two protein groups concerning the blood values except for $p$-urate (Table 5). However, in the whey group both insulin, glucose, and HOMA-IR increased significantly as compared to baseline values, most likely as a result of the higher intake of leucine since a long term stimulation of circulating leucine may affect the insulin-glucose homeostasis (43). Besides the insulin independent effect of leucine on the mTor pathway and MPS, leucine also promotes an insulin dependent effect by stimulation of the pancreas $\beta$-cells to secrete insulin and thereby further increase MPS (43).

IGF-1 is another anabolic biomarker, stimulating MPS, which may be associated to whey protein intake in postmenopausal women (44-46). The IGF-1 concentration was increased in both our protein groups and confirms this protein effect, also in line with the effect found by Heaney et al. after 2 years of milk supplementation (46).

The increased $6 \mathrm{MW}$ without change in muscle mass in the whey group can be a result of equal rates of MPS and muscle protein breakdown (MPB) at a high flux level of total muscle protein turnover (MPT) (47). Speculatively, it is possible that the muscle protein quality may have been improved due to an increased remodeling of muscle fibers leading to more effective functioning muscle tissue (47-49). It can be speculated that the $2.4 \%$ increase in $6 \mathrm{MW}$ in the placebo group during the study could indicate a specific effect of the carbohydrate supplement since there is some evidence of a carbohydrate stimulated effect on post exercise MPS when combined with amino acids (50). This might explain the small $2.4 \%$ but significant within increase in $6 \mathrm{MW}$ in the placebo group which is not evident in the soy protein group (with much lower carbohydrate in the supplement), but it should be emphasized that there were no significant differences when comparing the changes in the two groups.

Another interesting observation in this study was the decreased concentration in plasma urate in the whey group compared to the soy group. Urate is the end- product of purine degradation. These findings are in line with previous acute and short term investigations, where it was shown that milk proteins have a very low content of purines compared to soy protein (51-53). An elevated level of urate in plasma has been linked to the development of cardiovascular diseases (54-56) and is directly involved in the development of gout in patients (57). Thus, reduced levels of urate after whey protein intake may be associated with positive health effects in humans.

The increased level of urea in the two protein groups emphasizes good adherence to the dietary protocol during the intervention.

There are some limitations to the present study. Only 57 individuals completed this investigation with only 10 subjects in the placebo group and particularly, the low number in the placebo group makes a direct comparison between the protein groups and the placebo group statistically problematic. Also we included relatively healthy elderly people, whereas a population of more fragile elderly people could potentially have responded more strongly.

Another limitation of the study may be that the protein and leucine intake in the soy group was also rather high since in the soy group the daily intake of e.g. leucine was $6.75 \mathrm{~g}$ when habitual leucine intake from the food records was included, and if we divided this leucine content into 3 daily meals, the per meal intake was 2.25 g leucine which is rather close to the suggested threshold at $2.5-$ $2.8 \mathrm{~g}$ for healthy elderly people (15). Thus, this rather high intake of protein and leucine in the soy group may have affected the possibility to detect differences between the two protein groups.

Moreover, our four month-intervention may have been too short to detect differences between the dietary supplements. A six month-intervention with protein supplementation without exercise compared to placebo significantly increased physical function in frail elderly individuals (35). This indicates that a study of at least six month duration might have been appropriate to detect differences between the two protein groups.

It is of substantial importance that people perform physical activity and that they have a high quality protein intake in their diet during ageing (58). Our data support this current understanding and suggest that whey protein supplement, in addition to the effect of RT, has an impact on $6 \mathrm{MW}$ but the clinical importance of this effect is uncertain. Moreover, whey protein reduced the plasma urate which may have beneficial health effects as well.

In conclusion leucine-rich whey protein supplementation twice a day with concurrently RT, over a 16 -week period, had little effect on 6MW which presumably is of only very minor clinical importance in elderly people with osteopenia, and, moreover, had no effects on the other physical functional or strength tests or on muscle mass as compared with intake of soy protein. 
Acknowledgements: We thank Pia Hornbæk and Lenette Pedersen for their professional and skillful technical assistance. We thank Erik Jensen from Arla Foods Ingredients Group P/S (AFI) for providing the dietary supplements (the leucine-rich whey protein and the placebo product (maltrodextrin)) to the intervention. We thank for the donation of the IGF-1 and BP-3 kits which were provided by Immunodianostic systems Ltd, Bolton, England. We also thank for the donation of TheraBand exercise equipment which were provided by PROcare, Roskilde, Denmark and for the vitamin-D and calcium supplements (Unikalk Forte) provided by Axellus A/S, Ishøj, Denmark.

Contributions to the manuscript: BR, NM and JLM designed the research; JLM and KIN conducted research; BLL and SBP provided essential materials; JLM analyzed data; JLM wrote the paper with help from BR; JLM had primary responsibility for the final content; all authors have read and approved the final manuscript.

Conflicts of interest: Cand.scient. Mehlsen reports grants from the Danish Council for Strategic Research, during the conduct of the study; Dr. Pedersen Cand.scient. Nørgaard, and Dr. Møller have nothing to disclose. Dr. Langdahl reports grants from Danish Council for Strategic Research, during the conduct of the study; grants from Amgen, personal fees from Amgen, personal fees from Eli Lilly, personal fees from UCB, grants from Novo Nordisk, personal fees from Merck, outside the submitted work; Dr. Richelsen reports other connections with Arla Foods, Denmark, during the conduct of the study .

Ethical standard: The study protocols and procedures were conducted according to the Helsinki declarations and were approved by the ethics committee of the Central Region of Denmark. All participants signed a written informed consent.

\section{References}

1. McLeod M, Breen L, Hamilton DL, Philp A. Live strong and prosper: the importance of skeletal muscle strength for healthy ageing. Biogerontology. 2016 Jun;17(3):497-510.

2. Nair KS. Aging muscle. Am J Clin Nutr. 2005 May;81(5):953-63.

3. Muscaritoli M, Anker SD, Argiles J, Aversa Z, Bauer JM, Biolo G, et al. Consensus definition of sarcopenia, cachexia and pre-cachexia: joint document elaborated by Special Interest Groups (SIG) "cachexia-anorexia in chronic wasting diseases" and "nutrition in geriatrics". Clin Nutr. 2010 Apr;29(2):154-9.

4. Volpi E, Campbell WW, Dwyer JT, Johnson MA, Jensen GL, Morley JE, et al. Is the optimal level of protein intake for older adults greater than the recommended dietary allowance? J Gerontol A Biol Sci Med Sci. 2013 Jun;68(6):677-81.

5. Rodriguez NR. Introduction to Protein Summit 2.0: continued exploration of the impact of high-quality protein on optimal health. Am J Clin Nutr. 2015 Apr 29.

6. Bauer J, Biolo G, Cederholm T, Cesari M, Cruz-Jentoft AJ, Morley JE, et al. Evidence-based recommendations for optimal dietary protein intake in older people: a position paper from the PROT-AGE Study Group. J Am Med Dir Assoc. 2013 Aug; 14(8):542-59.

7. Leenders M, van Loon LJ. Leucine as a pharmaconutrient to prevent and treat sarcopenia and type 2 diabetes. Nutr Rev. 2011 Nov;69(11):675-89.

8. Dreyer HC, Drummond MJ, Pennings B, Fujita S, Glynn EL, Chinkes DL, et al. Leucine-enriched essential amino acid and carbohydrate ingestion following resistance exercise enhances mTOR signaling and protein synthesis in human muscle. Am J Physiol Endocrinol Metab. 2008 Feb;294(2):E392-400.

9. Bukhari SS, Phillips BE, Wilkinson DJ, Limb MC, Rankin D, Mitchell WK, et al. Intake of low-dose leucine-rich essential amino acids stimulates muscle anabolism equivalently to bolus whey protein in older women at rest and after exercise. Am J Physiol Endocrinol Metab. 2015 Jun 15;308(12):E1056-65.

10. Mitchell WK, Wilkinson DJ, Phillips BE, Lund JN, Smith K, Atherton PJ. Human Skeletal Muscle Protein Metabolism Responses to Amino Acid Nutrition. Adv Nutr. 2016 Jul 15;7(4):828S-38S.

11. Cuthbertson D, Smith K, Babraj J, Leese G, Waddell T, Atherton P, et al. Anabolic signaling deficits underlie amino acid resistance of wasting, aging muscle. FASEB J. 2005 Mar;19(3):422-4.

12. Ispoglou T, White H, Preston T, McElhone S, McKenna J, Hind K. Doubleblind, placebo-controlled pilot trial of L-Leucine-enriched amino-acid mixtures on body composition and physical performance in men and women aged 65-75 years. Eur J Clin Nutr. 2015 Jun 17.

13. English KL, Mettler JA, Ellison JB, Mamerow MM, Arentson-Lantz E, Pattarini JM, et al. Leucine partially protects muscle mass and function during bed rest in middle-aged adults. Am J Clin Nutr. 2016 Feb;103(2):46573.

14. Chale A, Cloutier GJ, Hau C, Phillips EM, Dallal GE, Fielding RA. Efficacy of whey protein supplementation on resistance exercise-induced changes in lean mass, muscle strength, and physical function in mobility-limited older adults. J Gerontol A Biol Sci Med Sci. 2013 Jun;68(6):682-90.

15. Bauer JM, Verlaan S, Bautmans I, Brandt K, Donini LM, Maggio M, et al. Effects of a vitamin D and leucine-enriched whey protein nutritional supplement on measures of sarcopenia in older adults, the PROVIDE study: a randomized, double-blind, placebo-controlled trial. J Am Med Dir Assoc. 2015 Sep 1;16(9):740-7.

16. Dillon EL, Sheffield-Moore M, Paddon-Jones D, Gilkison C, Sanford AP, Casperson SL, et al. Amino acid supplementation increases lean body mass, basal muscle protein synthesis, and insulin-like growth factor-I expression in older women. J Clin Endocrinol Metab. 2009 May;94(5):1630-7.

17. Verhoeven S, Vanschoonbeek K, Verdijk LB, Koopman R, Wodzig WK, Dendale $\mathrm{P}$, et al. Long-term leucine supplementation does not increase muscle mass or strength in healthy elderly men. Am J Clin Nutr. 2009 May;89(5):1468-75.

18. Meinert C. Dropout. In: Clinical Trials Handbook: Design and Conduct. Inc., Hoboken, NJ, USA.: John Wiley and Sons; 2012.

19. Aragon AA, Schoenfeld BJ. Nutrient timing revisited: is there a post-exercise anabolic window? J Int Soc Sports Nutr. 2013 Jan 29;10(1):5,2783-10-5.

20. Sundell J. Resistance Training Is an Effective Tool against Metabolic and Frailty Syndromes. Adv Prev Med. 2011;2011:984683.

21. Kerksick CM, Wilborn CD, Campbell BI, Roberts MD, Rasmussen CJ Greenwood M, et al. Early-phase adaptations to a split-body, linear periodization resistance training program in college-aged and middle-aged men. J Strength Cond Res. 2009 May;23(3):962-71.

22. Mikesky AE, Topp R, Wigglesworth JK, Harsha DM, Edwards JE. Efficacy of a home-based training program for older adults using elastic tubing. Eur J Appl Physiol Occup Physiol. 1994;69(4):316-20.

23. Colado JC, Garcia-Masso X, Triplett TN, Flandez J, Borreani S, Tella V. Concurrent validation of the OMNI-resistance exercise scale of perceived exertion with Thera-band resistance bands. J Strength Cond Res. 2012 Nov;26(11):3018-24.

24. ATS Committee on Proficiency Standards for Clinical Pulmonary Function Laboratories. ATS statement: guidelines for the six-minute walk test. Am J Respir Crit Care Med. 2002 Jul 1;166(1):111-7.

25. Perera S, Mody SH, Woodman RC, Studenski SA. Meaningful change and responsiveness in common physical performance measures in older adults. J Am Geriatr Soc. 2006 May;54(5):743-9.

26. Hardy SE, Perera S, Roumani YF, Chandler JM, Studenski SA. Improvement in usual gait speed predicts better survival in older adults. J Am Geriatr Soc. 2007 Nov;55(11):1727-34.

27. Buchner DM, Larson EB, Wagner EH, Koepsell TD, de Lateur BJ. Evidence for a non-linear relationship between leg strength and gait speed. Age Ageing. 1996 Sep;25(5):386-91.

28. Era P, Sainio P, Koskinen S, Haavisto P, Vaara M, Aromaa A. Postural balance in a random sample of 7,979 subjects aged 30 years and over. Gerontology. 2006;52(4):204-13.

29. Macsween A. The reliability and validity of the Astrand nomogram and linear extrapolation for deriving $\mathrm{VO} 2 \mathrm{max}$ from submaximal exercise data. J Sports Med Phys Fitness. 2001 Sep;41(3):312-7.

30. Perera S, Mody SH, Woodman RC, Studenski SA. Meaningful change and responsiveness in common physical performance measures in older adults. J Am Geriatr Soc. 2006 May;54(5):743-9.

31. Studenski S. What are the outcomes of treatment among patients with sarcopenia? J Nutr Health Aging. 2009 Oct;13(8):733-6.

32. Rondanelli M, Klersy C, Terracol G, Talluri J, Maugeri R, Guido D, et al. Whey protein, amino acids, and vitamin $\mathrm{D}$ supplementation with physical activity increases fat-free mass and strength, functionality, and quality of life and decreases inflammation in sarcopenic elderly. Am J Clin Nutr. 2016 Mar;103(3):830-40.

33. Nair KS, Schwartz RG, Welle S. Leucine as a regulator of whole body and skeletal muscle protein metabolism in humans. Am J Physiol. 1992 Nov;263(5 Pt 1):E928-34.

34. Rieu I, Balage M, Sornet C, Giraudet C, Pujos E, Grizard J, et al. Leucine supplementation improves muscle protein synthesis in elderly men independently of hyperaminoacidaemia. J Physiol. 2006 Aug 15;575(Pt 1):30515.

35. Tieland M, van de Rest O, Dirks ML, van der Zwaluw N, Mensink M, van Loon LJ, et al. Protein supplementation improves physical performance in frail elderly people: a randomized, double-blind, placebo-controlled trial. J Am Med Dir Assoc. 2012 Oct;13(8):720-6.

36. Bonnefoy M, Cornu C, Normand S, Boutitie F, Bugnard F, Rahmani A, et al. The effects of exercise and protein-energy supplements on body composition and muscle function in frail elderly individuals: a long-term controlled randomised study. Br J Nutr. 2003 May;89(5):731-9.

37. LIFE Study Investigators, Pahor M, Blair SN, Espeland M, Fielding R, Gill TM, et al. Effects of a physical activity intervention on measures of physical performance: Results of the lifestyle interventions and independence for Elders Pilot (LIFE-P) study. J Gerontol A Biol Sci Med Sci. 2006 Nov;61(11):1157-65.

38. Latham NK, Harris BA, Bean JF, Heeren T, Goodyear C, Zawacki S, et al. Effect of a home-based exercise program on functional recovery following rehabilitation after hip fracture: a randomized clinical trial. JAMA. $2014 \mathrm{Feb}$ 19;311(7):700-8.

39. Pahor M, Guralnik JM, Ambrosius WT, Blair S, Bonds DE, Church TS, et al. Effect of structured physical activity on prevention of major mobility 
disability in older adults: the LIFE study randomized clinical trial. JAMA. 2014 Jun 18;311(23):2387-96.

40. Bijlsma AY, Pasma JH, Lambers D, Stijntjes M, Blauw GJ, Meskers CG, et al. Muscle strength rather than muscle mass is associated with standing balance in elderly outpatients. J Am Med Dir Assoc. 2013 Jul;14(7):493-8.

41. Granacher U, Gollhofer A, Hortobagyi T, Kressig RW, Muehlbauer T. The importance of trunk muscle strength for balance, functional performance, and fall prevention in seniors: a systematic review. Sports Med. 2013 Jul;43(7):62741.

42. Tittelbach TJ, Mattes RD, Gretebeck RJ. Post-exercise substrate utilization after a high glucose vs. high fructose meal during negative energy balance in the obese. Obes Res. 2000 Oct;8(7):496-505.

43. Xu G, Kwon G, Cruz WS, Marshall CA, McDaniel ML. Metabolic regulation by leucine of translation initiation through the mTOR-signaling pathway by pancreatic beta-cells. Diabetes. 2001 Feb;50(2):353-60.

44. Zhu K, Meng X, Kerr DA, Devine A, Solah V, Binns CW, et al. The effects of a two-year randomized, controlled trial of whey protein supplementation on bone structure, IGF-1, and urinary calcium excretion in older postmenopausal women. J Bone Miner Res. 2011 Sep;26(9):2298-306.

45. Schurch M, Rizzoli R, Slosman D, Vadas L, Vergnaud P, Bonjour J. Protein Supplements Increase Serum Insulin-Like Growth Factor-I Levels and Attenuate Proximal Femur Bone Loss in Patients with Recent Hip Fracture. Ann Intern Med. 1998 05/15;128(10):801-9.

46. Heaney RP, McCarron DA, Dawson-Hughes B, Oparil S, Berga SL, Stern JS, et al. Dietary changes favorably affect bone remodeling in older adults. J Am Diet Assoc. 1999 Oct;99(10):1228-33.

47. Wolfe RR. Update on protein intake: importance of milk proteins for health status of the elderly. Nutr Rev. 2015 Aug;73 Suppl 1:41-7.

48. Conroy MB, Kwoh CK, Krishnan E, Nevitt MC, Boudreau R, Carbone LD, et al. Muscle strength, mass, and quality in older men and women with knee osteoarthritis. Arthritis Care Res (Hoboken). 2012 Jan;64(1):15-21.
49. Balagopal P, Rooyackers OE, Adey DB, Ades PA, Nair KS. Effects of aging on in vivo synthesis of skeletal muscle myosin heavy-chain and sarcoplasmic protein in humans. Am J Physiol. 1997 Oct;273(4 Pt 1):E790-800.

50. Miller SL, Tipton KD, Chinkes DL, Wolf SE, Wolfe RR. Independent and combined effects of amino acids and glucose after resistance exercise. Med Sci Sports Exerc. 2003 Mar;35(3):449-55.

51. Garrel DR, Verdy M, PetitClerc C, Martin C, Brule D, Hamet P. Milk- and soy-protein ingestion: acute effect on serum uric acid concentration. Am J Clin Nutr. 1991 Mar;53(3):665-9.

52. Dalbeth N, Wong S, Gamble GD, Horne A, Mason B, Pool B, et al. Acute effect of milk on serum urate concentrations: a randomised controlled crossover trial. Ann Rheum Dis. 2010 Sep;69(9):1677-82.

53. Liu ZM, Ho CS, Chen YM, Woo J. Can soy intake affect serum uric acid level? Pooled analysis from two 6-month randomized controlled trials among Chinese postmenopausal women with prediabetes or prehypertension. Eur J Nutr. 2015 Feb;54(1):51-8.

54. Holme I, Aastveit AH, Hammar N, Jungner I, Walldius G. Uric acid and risk of myocardial infarction, stroke and congestive heart failure in 417,734 men and women in the Apolipoprotein MOrtality RISk study (AMORIS). J Intern Med. 2009 Dec;266(6):558-70.

55. Oda E, Kawai R, Sukumaran V, Watanabe K. Uric acid is positively associated with metabolic syndrome but negatively associated with diabetes in Japanese men. Intern Med. 2009;48(20):1785-91.

56. Jin YL, Zhu T, Xu L, Zhang WS, Liu B, Jiang CQ et al. Uric acid levels, even in the normal range, are associated with increased cardiovascular risk: the Guangzhou Biobank Cohort Study. Int J Cardiol. 2013 Oct 3;168(3):2238-41.

57. Beyl RN. Update on Importance of Diet in Gout. Am J Med. 2016 $-11 ; 129(11): 1153 ; 1153,1158 ; 1158$.

58. Paddon-Jones D, Campbell WW, Jacques PF, Kritchevsky SB, Moore LL Rodriguez NR, et al. Protein and healthy aging. Am J Clin Nutr. 2015 Apr 29. 